
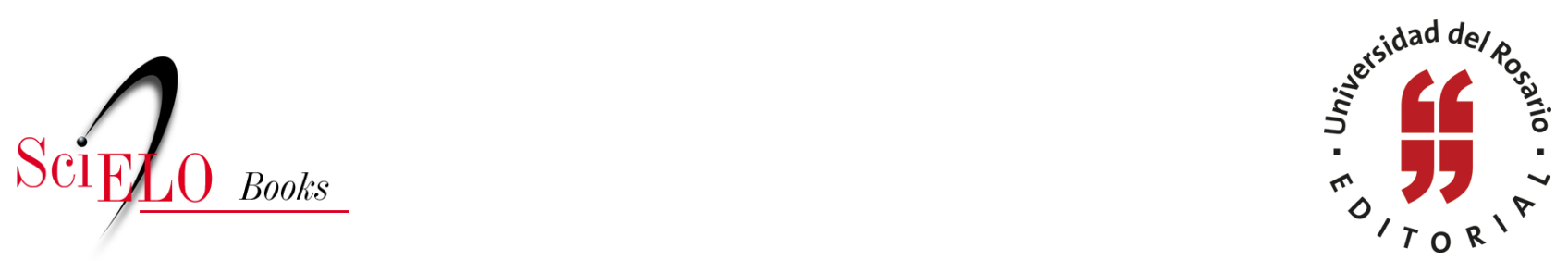

\title{
21. Ellos tienen su inglés y lo entienden a uno
}

\author{
César Augusto Tapias Hernández
}

\section{SciELO Books / SciELO Livros / SciELO Libros}

TAPIAS HERNÁNDEZ, C.A. Ellos tienen su inglés y lo entienden a uno. In: Historias de familia: Etnografía delirante sobre el amor, la violencia y las drogas [online]. Bogotá: Editorial Universidad del Rosario, 2014, pp. 89-92. Textos de ciencias humanas collection. ISBN: 978-958-738-543-4. https://doi.org/10.7476/9789587385434.0022.

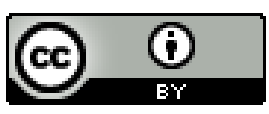

All the contents of this work, except where otherwise noted, is licensed under a Creative Commons Attribution 4.0 International license.

Todo o conteúdo deste trabalho, exceto quando houver ressalva, é publicado sob a licença Creative Commons Atribição 4.0.

Todo el contenido de esta obra, excepto donde se indique lo contrario, está bajo licencia de la licencia $\underline{\text { Creative }}$ Commons Reconocimento 4.0 . 


\title{
21. Ellos tienen su inglés y lo entienden a uno
}

\author{
We led a sheltered life out there in the suburbs. New York was \\ only twenty miles away, but it could have been China for all it \\ had to do with our little world of lawns and wooden houses. * \\ Paul Auster, The Locked Room
}

En las dos oportunidades en que el tío Mario ha estado en Nueva Jersey, donde sus hijas Nelly y Mery, como que se las ha pasado no más que hablando en español. Y aun cuando muchos aprovecharían un viaje de esos para aprender otro idioma, dado los beneficios culturales que tendría, sin destacar los económicos, al tío eso como que poco le importa, y eso porque sin el idioma ha podido trabajar. La última vez, en solo tres meses, se consiguió algo más de 1500 dólares.

- Primero - cuenta el tío - 'tuve trabajando pintándole la casa a la suegra de Nelly, después empacando una mercancía para llevarla de un almacén a otro. Eran muchas cajas, entonces eso fue trabajo como de una semana. También 'tuve por ahí podando jardines y, bueno, me conseguí unos dolaritos con los que les puse puertas de madera a las habitaciones de la casa en Colombia. La pintura sí fue una plata que me mando Mery en diciembre...

- Vos has trabajado toda la vida, ¿no?, tío.

—Toda la vida, mijo, toda la vida... ¡Desde chiquito!

Mi tío Mario tiene 65 años; es el segundo en la familia de mi mamá, después de Iván, si hablamos de los hombres solamente. Fue el último en dejar el pueblo de Titiribí, al sur de la provincia... Solo emigró a la capital de la montaña después de muerta mi abuela Laura, y eso dizque porque no le gustaba venirse pa’ Medellín a

* "Llevábamos una vida protegida en los suburbios. Nueva York estaba a solo veinte kilómetros de distancia, pero podría haber sido China considerando lo poco que tenía que ver con nuestro pequeño mundo de jardines y las casas de madera”. 
pagar arriendo. Vivió un tiempo en la casa de los abuelos en el barrio El Pedregal, hasta que consiguió un lote por los lados del 12 de Octubre, un barrio más alto en las laderas occidentales de la ciudad. Ahí vive todavía, en una casa a la que todavía le meten plata: los dólares que hacen las muchachas en Nueva Jersey y lo que le deja un puestico de mangos que desde hace años tiene junto a la iglesia del barrio El Pedregal.

- ¿Qué hacías en el pueblo, allá en Titiribí, tío Mario?

-Un tiempo 'tuve trabajando por allá en una finca, sacando cabuya.

— ¿Cabuya? Yo sabía que en Titiribí era posible el café y al caña de azúcar; pero de la cabuya...

-Ah, pues eso sale de la penca. Uno mete cada hoja y la máquina esa...

— ¿Un molino como lo que se usan con la caña para el guarapo o qué?

-Humm, no... ¡Una máquina para hacer cabuya, llama eso. Tiene una cuchilla o algo pues... como de filo. Empuja uno la hoja hasta el medio, y sale una tira. Saca la hoja y la voltea y vuelve a meterla... Y así.

- ¿Y lista la cabuya?

- No. Eso hay que lavarlo y después ponerlo a sol. Se trae pa' Medellín y ya con eso hacen costales y todo eso, son bultos de fique lo que uno termina haciendo en la finca.

-Y ¿qué te tocaba hacer en todo ese proceso?

-Yo hice de todo: cortar, meter al molino... También en el lavado y la extendida, HASTA CARGUÉ LOS BULTOS; pero eso era cuando yo vivía en el campo, porque cuando me vine pa'l pueblo, trabajaba recogiendo café, y los fines de semana, sacaba un puesto de ventas de mangos en el parque.

- ¿Y fue que conseguiste casa ahí en el parque?

- Primero sí pagaba arriendo, después compré una casita que vendí luego pa' venirme para Medellín.

- ¿Y en el campo dónde vivías?

-En la casa del patrón.

- ¿Con toda la familia?

- ¡Claro, hermano!

El tío también cuenta cosas sobre Nueva Jersey, que TODo es muy bonito, aunque no le ha tocado las olas de calor:

-Dicen que son épocas muy bravas. Ahí de pronto bajábamos a Nueva York y no más cuando se trata de pasear, de conocer... 
—Y eso de bajar a Nueva York... ¿es como si uno fuera al centro de la ciudad desde aquí, o qué?

Que todo es bien frío. Tanto así que la gente no hace fiesta en la calle, como por aquí. Que todo el mundo es en la casa o en las tabernas. Las calles son frías, solas y blancas por la nieve

- ¿Aprendiste a decir algo en inglés?

-No, ah, qué va. Lo mejor de por allá es que ellos tienen su inglés y lo entienden a uno. Hay quien hable los dos idiomas. Entonces pa' qué.

— ¿Ya no sacas tu puesto de mangos en El Pedregal?

- Sí, pero los sábados y domingos. Esto ya ta’ muy malo, hermano. Mejor me quedo por aquí.

- ¿Cuándo regresas por allá?

—Cuando se mejore Luz.

Luz, su esposa, se accidentó hace algunos meses: rodó por unas escalas y se fracturó. Solo puede caminar con la ayuda de un caminador; por eso en la casa del tío permanece a diario Miriam, otra de sus hijas, y con ella, algunos de los hombres: Óscar, Jairo..., y mucho peladito, entre ellos Andrés, el hijo de la Mery, que un día viajará adonde su mamá, allá en Nueva Jersey.

Me dice el tío que se ha hecho de todo y nada que lo dejan salir —o entrar, pienso yo - . Viendo al pelao ese, recuerdo a la prima Mery, ella igual que Nelly, se la llevaban muy bien con mamá cuando eran más jóvenes. Sobre todo Nelly. Una vez, no sé por qué, la Mery amaneció en casa. Yo era un chino de unos pocos años; pero recuerdo que ella era muy linda, y se desvestía en la habitación de mi hermano y me ordenaba taparme con la cobijas. Yo obedecía, entonces la imaginaba desnuda, solo la imaginaba. Finalmente era yo obediente o, a lo mejor, muy dormido... Su piel era muy blanca, todo su cuerpo también... Podía imaginarlo.

Antes de despedirme le pregunté al tío Mario que cómo así que en sus tiempos mozos a él le decían "Cucharada”, allá en Titiribí. Él apenas se sonríe diciendo que la gente tiene ese vicio de rebautizar a los demás por cualquier cosa; pero yo le digo que conozco la razón, y que la verdad no es que sea cualquier cosa:

-Que porque te metías en cualquier conversación y hasta opinabas.

- ¿Vos cómo supiste eso, muchacho?

—Estuve en Titiribí hace algunos días.

Y apenas se sonríe el tío Mario, de nuevo...

—¿Qué hay de tu papá, muchacho? - me pregunta el tío como para finalizar la conversa en torno a sus aventuras-. ¿Sigue bebiendo todos los días? 
-iClaro!

- ¿Y quién de ustedes le sacó el gusto por el trago?

Mi tío de cabeza calva ya, cubierta con un sombrero, igualito a como hacía el papito Gabriel, continúa preguntando, y antes de responderle, viéndolo, pienso...

- Todos dicen que mi hermano - es la respuesta que le doy.

— ¿No te pensás ir por allá, muchacho? Hoy en día, pa’l que estudie o pa’l bruto. Aquí en Colombia no hay nada que hacer...

Yo asiento mientras le digo que a lo mejor sí me vaya; pero, pensándolo bien, que lo que es ventaja para el tío Mario, para mí no lo es tanto. Qué pereza estar rodeado de latinos, colombianos para más señas o cubanos en el mejor de los casos, todos hablando español. Mejor me quedo aquí o me regreso a La Habana. 